\title{
Protective Effect of Citrulline on the methotrexate - induced cardiac muscle toxicity in male albino rats: Histological and immunohistochemical study
}

\section{Original Article}

\author{
Ghada A. Elsammak, Samar Abdelaziz Mostafa, and Samar Mohamed Reda \\ Departments of of Histology and Cell Biology, Faculty of Medicine, Zagazig University, \\ Zagazig, Egypt.
}

\begin{abstract}
Background and Objectives: Methotrexate (MTX) is a worldwide drug used to treat neoplastic and non-neoplastic diseases despite its severe side-effects. The present study aimed to throw more light on the MTX effects on cardiac muscle of adult male albino rats and the possible protective role of L-citrulline.

Materials and Methods: Thirty Adult male albino rats were used and equally divided into three Groups: Group I: control, Group II (MTX treated), Group III (MTX and L-citrulline treated). Left ventricular specimens were prepared for H and E, Mallory trichrome staining, immunohistochemical analysis for TLR2 and electron microscope examination.

Results: Cardiac muscles of MTX treated rats (Group II) showed histological, ultrastructural and histochemical changes such as dark stained nuclei, vacuolation, pyknotic nuclei, loss of striations and interrupted intercalated disc. Increased collagen fibers were also found. Minimal changes were observed in Group III (MTX and L-citrulline treated).

Conclusion: MTX has a deleterious effect on rat cardiac muscle and administration of L-citrulline has a protective effect.
\end{abstract}

Key Words: Cardiac muscle, L-citrulline, methotrexate, myofibrils, TLR2.

Revised: 28 July 2020, Accepted: 27 August 2020.

Corresponding Author: Ghada A. Elsammak , MD, Department of Histology and Cell Biology, Faculty of Medicine, Zagazig University, Zagazig, Egypt, Tel.: 00201222364470, E-mail: Ghadaelsammak@hotmail.com

ISSN:2536-9172, June 2020, Vol. 4, No. 1

\section{INTRODUCTION}

Methotrexate (MTX), a structural analogue of folic acid, is widely used as a chemotherapeutic agent for neoplasm treatment as acute leukaemia, lung and breast cancers ${ }^{[1]}$. It is also recommended for non-neoplastic diseases as psoriasis and autoimmune diseases as rheumatoid arthritis ${ }^{[2]}$.

Using MTX at cyclic high doses to treat malignant tumors can be associated with severe hepatotoxicity and acute renal failure ${ }^{[3]}$, while its chronic use at lower doses may cause progressive liver fibrosis, uremia, and hematuria ${ }^{[4]}$. Some cardiac dysfunctions could be detected by previous studies after using methotrexate ${ }^{[5]}$. Since it is essential drug for treatment of many diseases, many trials were done to attenuate its side effects especially on the vital organs as the heart.

L-Citrulline is a colorless water-soluble amino acid that is a potent endogenous precursor of L-arginine. It is first identified from the juice of watermelon. It was later obtained from tryptic digestion of casein ${ }^{[6]}$.

In a recent clinical study, L-citrulline supplementation dose-dependently increases plasma L-arginine (L-Arg) levels in healthy human volunteers more effectively than equivalent doses of $\mathrm{L}$-arginine itself $\mathrm{f}^{[7]}$. Orally administered L-arginine is known to be extensively metabolized by bacteria in the gut, and arginase in the gut and liver. However, oral L-citrulline administration was shown to avoid such metabolisms. Accordingly, oral L-citrulline supplementation was reported to increase L-Arginine levels more efficiently than oral L-Arg administration itself and increased nitric oxide production ${ }^{[8]}$.

Toll-like receptors (TLRs) represent the first line of host defense against microbial infection and play a pivotal role in both innate and adaptive immunity. TLRs can also function as a sensor responding to tissue stress such as hypoxia and ischemia and modulate cell survival and tissue injury ${ }^{[9]}$.

The aim of this work is to study the possible histological alterations that may occur in the cardiac muscle structure of adult male albino rats receiving MTX and the possible protective role of L-citrulline supplementation.

\section{MATERIALS AND METHODS}

\section{Chemicals:}

Methotrexate was purchased from Shanxi PUDE Pharmaceutical Company (Shanxi, China) in the form of vials $50 \mathrm{mg} / 2 \mathrm{ml}$. L-citrulline was obtained from Sigma chemical Co. 


\section{Experimental animals:}

Thirty adult male albino rats (13-16 weeks old), with an average weight of 200-250 gm were used in this study. They were obtained from breading animal house, Faculty of Medicine, Zagazig University. Experimental protocol was approved by the Zagazig University Research Ethics Committee. Throughout the duration of the experiment, the rats were housed at room temperature with normal light/ dark cycles and were allowed ad-libitum access to food and water. The animals were divided into three groups each of them consists of 10 rats.

Group I (control group): 10 rats were injected intraperitoneally with saline. Group II (methotrexate treated group): rats were intraperitoneally injected with methotrexate at the dose $5 \mathrm{mg} / \mathrm{kg} /$ day for one month ${ }^{[10]}$.

Group III (methotrexate concomitant with citrulline group): rats were injected intraperitoneally with methotrexate at the same previous dose $(5 \mathrm{mg} / \mathrm{kg} /$ day $)$ in concomitant with oral administration of $900 \mathrm{mg} / \mathrm{kg}$ of L-citrulline for one month using intragastric tube ${ }^{[11]}$.

\section{Methods:}

After 24 hours from the last dose, rats were anesthetized using ether inhalation, sacrificed, carefully dissected and specimens from the left ventricle were processed for light and electron microscopic examination.

\section{Light microscope technique:}

For light microscopy, the specimens were immersed in $10 \%$ neutral-buffered formalin, washed, dehydrated, cleared, and embedded in paraffin. Sections of $5 \mu \mathrm{m}$ thickness were stained with H\&E and Mallory's trichrome to assess the degree of cardiac muscle alterations ${ }^{[12]}$. For immunohistochemistry, 5- $\mu$ m-thick sections were dewaxed, rehydrated, and washed with PBS. The sections were incubated in hydrogen peroxide for 10 minutes to block the endogenous peroxidase then incubated overnight in a humid chamber with the primary antibody at $4^{\circ}$ Cat dilution of 1:100 for localization of TLR-2. The primary antibody was rabbit monoclonal anti-rat Tolllike receptor 2 (TLR2) antibody (ab108998; Abcam, Cambridge, Massachusetts, USA). The sections were then rinsed three times in PBS and incubated with the corresponding biotinylated secondary antibody for $1 \mathrm{~h}$ at room temperature. Streptavidin peroxidase was then added for $10 \mathrm{~min}$ and the specimens were rinsed again three times in PBS. Immunoreactivity was visualized using 3,3'-diaminobenzidine as a chromogen. The sections were counterstained with Mayer's hematoxylin. Negative control sections were prepared by excluding the primary antibodies ${ }^{[13]}$. Positive control for TLR2 was LPS (Lipopolysaccharide)-stimulated THP1 cells.
TLR2-immunostained heart sections were considered positive upon expressing clear evident brown cytoplasmic coloration. Sections were viewed using an Olympus microscope (C5060-AUD, 5H01155 JAPAN) and images were captured by a digital camera (Canon PowerShot A620, England, UK).

The scale bar was added to the photomicrographs according calibration sheet using power point (https:// www. youtube.com/watchv=3bynnPQQxmg).

\section{Transmission electron microscope technique:}

For transmission electron microscopy, the specimens were fixed in $2.5 \%$ buffered glutaraldehyde for 2 hours at $4^{\circ} \mathrm{C}$, washed in PBS and fixed in $1 \%$ osmium tetroxide in distilled water for 2 hours at $4^{\circ} \mathrm{C}$, then dehydrated in alcohol and embedded in epoxy resins. Semithin sections (1- $\mu \mathrm{m}$-thick) were obtained and stained with $1 \%$ toluidine blue and examined under a light microscope and ultrathin sections $(70-90 \mathrm{~nm})$ were stained with uranyl acetate and lead citrate $^{[14]}$. The ultrathin sections were examined and photographed using a JEOL JEM 2100 EXII Electron Microscope (Jeol Ltd), Electron Microscope Research Laboratory, Faculty of Agriculture, Mansoura University, Egypt.

\section{Morphometric study:}

The image analyzer computer system Leica Qwin 500 (Leica Ltd, Cambridge, UK) at the Image Analyzing Unit of Pathology Department, Faculty of Dentistry, Cairo University, Egypt, was used to measure the area percent of collagen fibers and optical density of immunoreaction for TLR2 at a magnification X400. The area percent was measured using the interactive measure menu. The measuring frame of a standard area equal to $118476.6 \mathrm{~mm}^{2}$ was chosen so that the brown positive immune reaction could be seen and masked by blue binary colour to be measured. Examination of ten readings from five nonoverlapping sections from each rat of all groups was done.

\section{Statistical analysis:}

All values of the experiments were represented as mean \pm Standard Deviation (SD). One-way analysis of variance (ANOVA) was used, followed by Post hoc least significant difference (LSD) test to evaluate the differences between the groups. All analyses were performed using the IBM SPSS 19.0 software ${ }^{[15]}$. 


\section{RESULTS}

\section{I-Light and Electron microscope results:-}

Light microscopic examination of heart sections from the control group showed longitudinally and transversely arranged muscle fibers with acidophilic cytoplasm and central oval vesicular nuclei. Those fibers were branching and anastomosing with each other (Fig.1).

Electron microscopic examination of heart sections from the control group showed a cardiomyocyte with a single euchromatic oval nucleus (Fig.2A). Bundles of myofibrils were seen with alternating dark and light bands. $\mathrm{Z}$ lines were observed in the middle of I bands. (Fig.2A $\&$ B). Portions of cardiomyocytes were joined at an intercalated disc (Fig.2C). Numerous mitochondria were found around the nucleus and in between the myofibrils and arranged in rows (Fig.2A, B\&C).

Light microscopic examination of heart sections from the Methotrexate-treated group showed distorted cardiac muscle fibers with many vacuolations. There were condensed nuclei with congested blood vessels (Fig.3).

Electron microscopic examination of heart sections from the Methotrexate-treated group showed a cardiomyocyte having an indented nucleus with irregular nuclear envelope. Mitochondria with variable sizes and shapes were observed while others with destructed cristae. Dilated blood capillary was also seen (Fig.4A). There were bundles of collagen fibrils. Accumulated groups of mitochondria and numerous glycogen granules were seen (Fig.4B). Areas of myofibrillar loss were noticed (Fig.4A \& B). Interrupted intercalated disk, mitochondria with disrupted cristae and small vacuoles were seen (Fig.4C).

Light microscopic examination of heart sections from the Methotrexate-Citrulline treated group showed cardiac muscle fibers with preserved normal architecture and large oval vesicular nuclei. Some cellular infiltrate was seen with some congested blood capillaries (Fig.5).

Electron microscopic examination of heart sections from the Methotrexate-Citrulline treated group showed a cardiomyocyte with euchromatic nucleus. Numerous mitochondria in the perinuclear area and some glycogen granules were noticed. There were more or less normal myofibrils arrangement (Fig.6A). Some myofibrils were well organized into alternating dark and light bands while others were discontinued. There were regularly arranged mitochondria and others with variable size and shape. Intact intercalated disc was observed (Fig.6B).

Light microscopic examination of Mallory's trichrome stained sections of cardiac muscle revealed blue-stained collagen fibers which were scanty in the control group (Fig.7A), marked in the Methotrexate -treated group (Fig.7B) and moderate in the Methotrexate-Citrulline treated group (Fig.7C) in between muscle fibers and around blood vessels.
Lightmicroscopic examination ofimmunohistochemical stained sections for Toll-like receptor 2 (TLR2) showed positive cytoplasmic immunoreaction which was weak in few cardiac muscle cells in the control group (Fig.8A), strong in many cardiac muscle cells in the Methotrexate -treated group (Fig.8B) and moderate in some cardiac muscle cells in the Methotrexate-Citrulline treated group (Fig.8C).

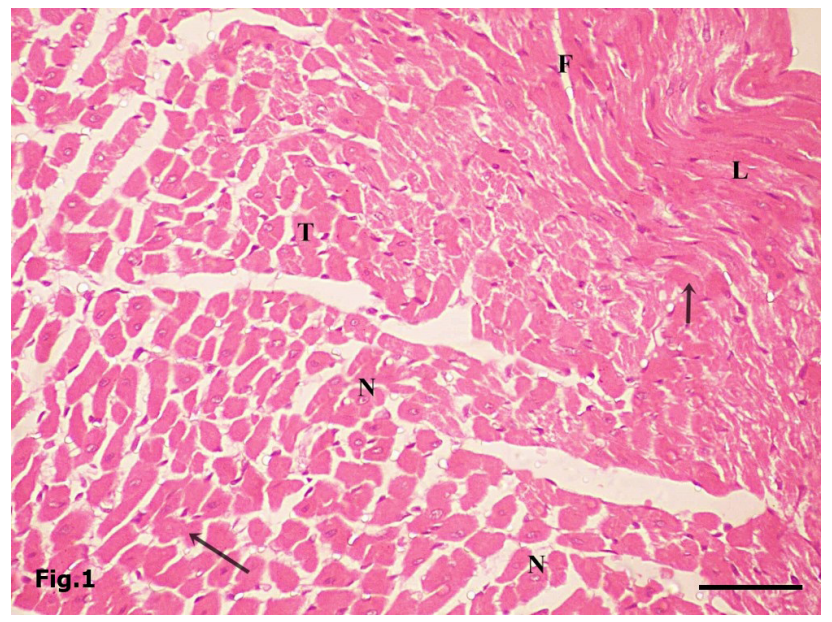

Fig.1: A photomicrograph of a section of cardiac muscle of a control rat (group I) showing longitudinally (L) and transversely $(\mathrm{T})$ arranged cardiac muscle fibers with acidophilic cytoplasm (arrows) and central oval vesicular nuclei $(\mathrm{N})$. The fibers are branching and anastomosing with each other (F). (H\&E, x 400; scale bar=30um).

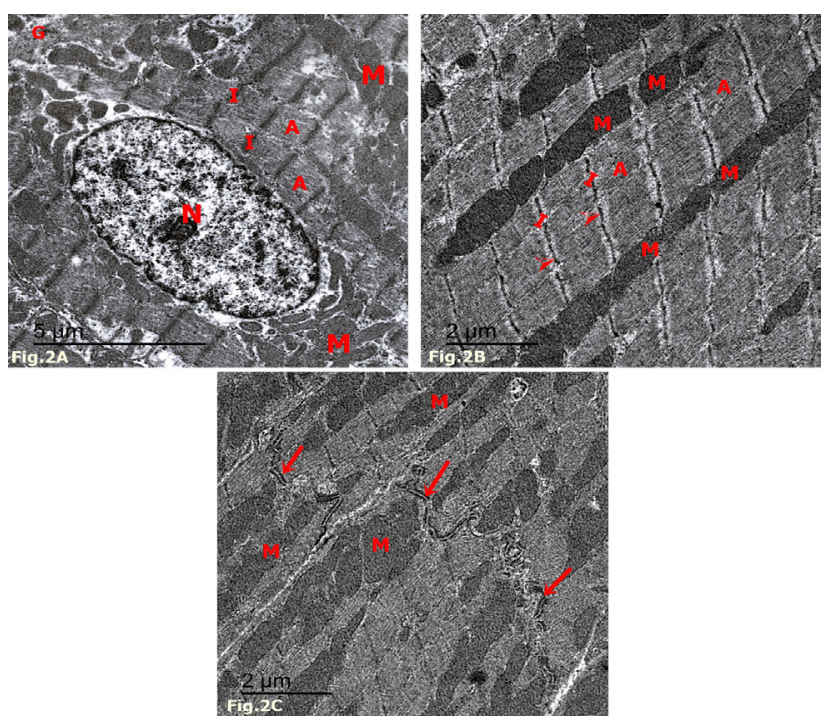

Fig.2: An electron micrograph of cardiac muscle of a control rat (group I) showing (2A): a cardiomyocyte with a single euchromatic oval nucleus $(\mathrm{N})$. Numerous mitochondria $(\mathrm{M})$ are found around the nucleus and in between the myofibrils. Bundles of myofibrils are seen with alternating dark (A) and light bands (I). Glycogen granules $(\mathrm{G})$ are seen. $(2 \mathrm{~B})$ : The normal striations of cardiac muscle cell are seen showing alternating dark (A) and light (I) bands. $\mathrm{Z}$ lines (arrow heads) are observed in the middle of I bands. Numerous intermyofibrillar mitochondria (M) are elongated and regularly aligned in rows. (2C): Portions of cardiomyocytes are joined at an intercalated disc (arrows). Rows of mitochondria (M) are seen in between myofibrils.

(TEM: Ax9000, B\&Cx13.000). 

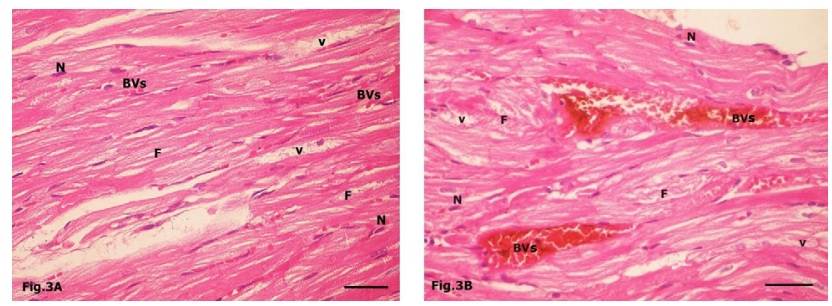

Fig.3 (A\&B): A photomicrograph of a section of cardiac muscle of a methotrexate-treated rat (group II) showing distorted cardiac muscle fibers $(\mathrm{F})$ with many vacuolations $(\mathrm{v})$. The nuclei are condensed $(\mathrm{N})$. There are congested blood vessels (BVs). (H\&E, x 400; scale bar=30um).

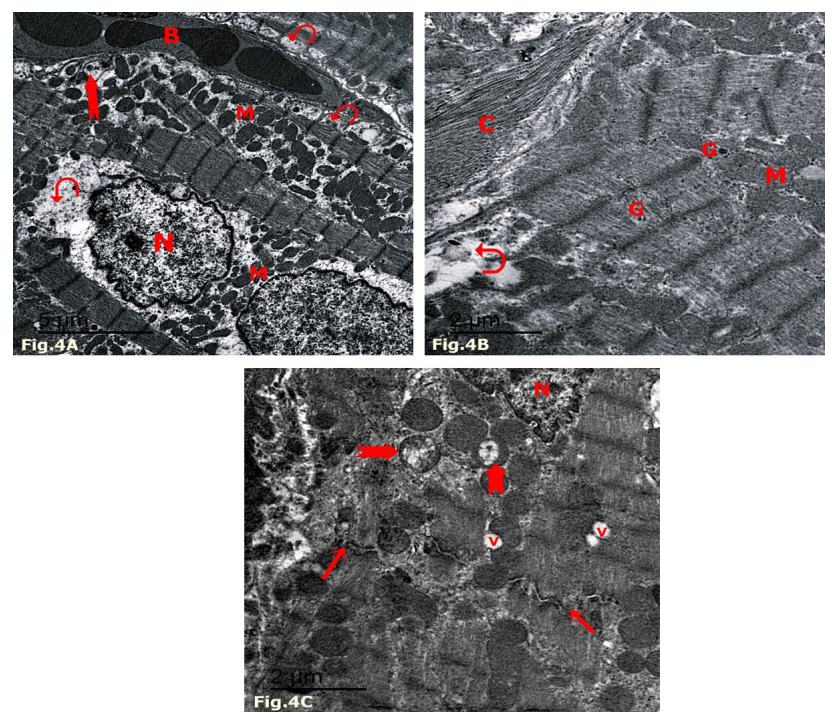

Fig.4: An electron micrograph of cardiac muscle of a methotrexate-treated rat (group II) showing (4A): a cardiomyocyte having an indented nucleus with irregular nuclear envelope $(\mathrm{N})$. Mitochondria with variable sizes and shapes $(\mathrm{M})$ are observed. Other mitochondria with destructed cristae (notched arrow) are also observed. Areas of myofibrillar loss (curved arrows) and dilated blood capillary (B) are seen. (4B): There are bundles of collagen fibrils (C). Accumulated groups of mitochondria (M) are seen. Numerous glycogen granules $(G)$ are noticed. (4C): a cardiomyocyte having heterochromatic nucleus with irregular nuclear envelope $(\mathrm{N})$. Interrupted intercalated disk (arrows), mitochondria with disrupted cristae (notched arrow) and small vacuoles )v) are seen. (TEM: Ax6000, B\&Cx13.000),

(Scale bar: $\mathrm{A}=5 \mathrm{um}, \mathrm{B} \& \mathrm{C}=2 \mathrm{um}$ ).

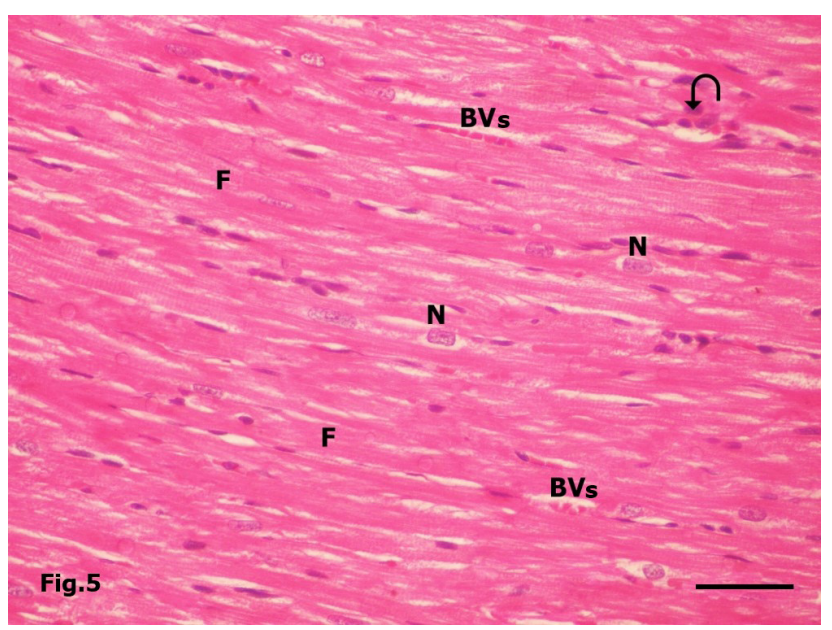

Fig.5: A photomicrograph of a section of cardiac muscle of animals treated with methotrexate concomitant with Citrulline (group III) showing most of cardiac muscle fibers with preserved normal architecture (F) and large oval vesicular nuclei $(\mathrm{N})$. Some cellular infiltrate is seen (curved arrow). Notice some congested blood capillaries (BVs). (H\&E, x 400; scale bar=30um).
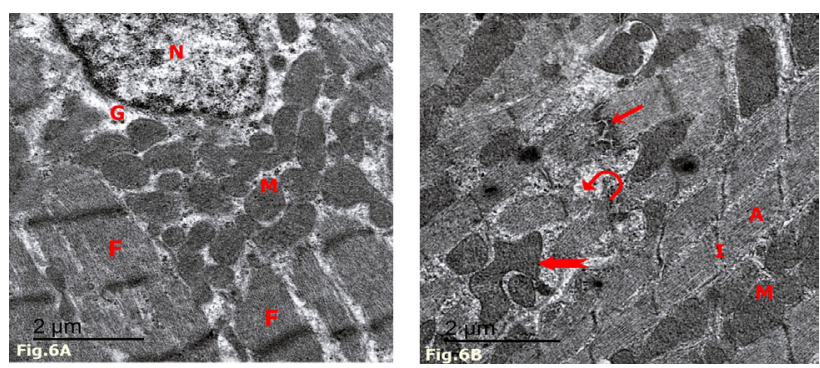

Fig.6: An electron micrograph of cardiac muscle of animals treated with methotrexate concomitant with Citrulline (group III) showing (6A): a cardiomyocyte with euchromatic nucleus $(\mathrm{N})$. There are more or less normal myofibrils (F) arrangement. Numerous mitochondria $(\mathrm{M})$ in the perinuclear area are seen. Some glycogen granules $(\mathrm{G})$ are noticed. (6B): Some myofibrils are well organized into alternating dark (A) and light (I) bands while others are discontinued (curved arrow). Regularly arranged mitochondria $(\mathrm{M})$ are seen. Other mitochondria (notched arrow) appear with variable size and shape. Intact intercalated disc (arrow) is observed. (TEM: Ax16.000, Bx16.000), (Scale bar: $A \& B=2 u m$ ) 

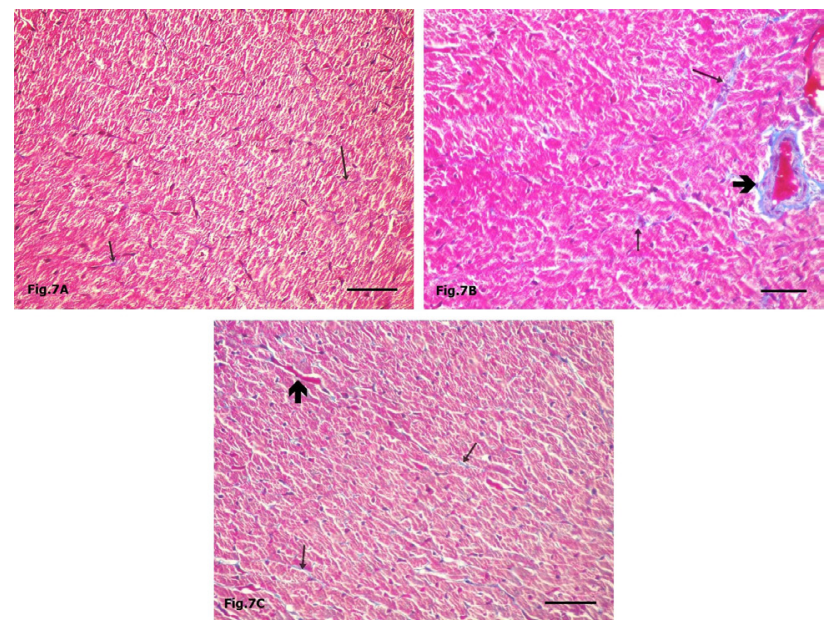

Fig.7: A photomicrograph of a section of cardiac muscle showing blue-stained collagen fibers which are scanty (arrows) in the control group (7A), marked in the Methotrexatetreated group (7B) and moderate in the MethotrexateCitrulline treated group $(7 \mathrm{C})$ in between muscle fibers (thin arrows) and around blood vessels (thick arrows). (Mallory's trichrome, $\mathrm{x} 400$; scale bar=30um).

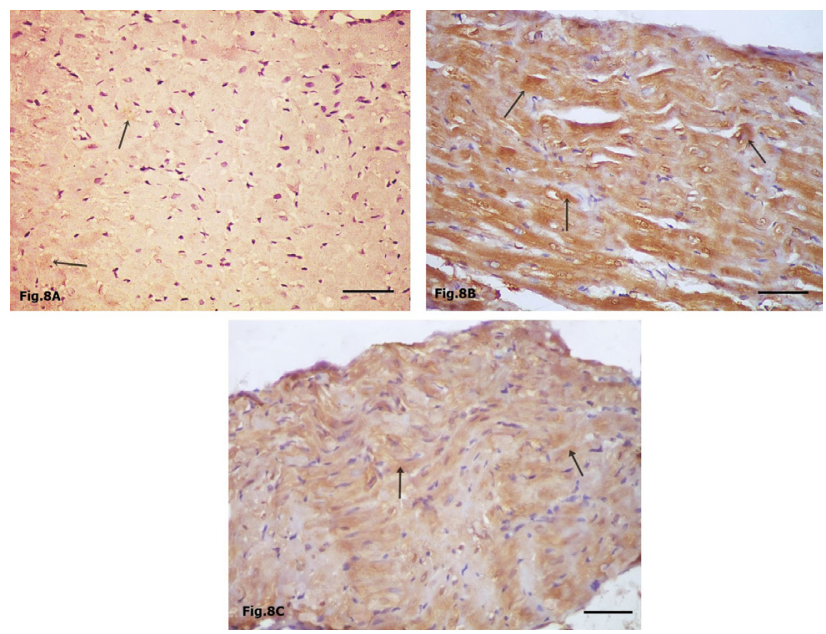

Fig.8: A photomicrograph of a section of cardiac muscle showing cytoplasmic immunoreaction for toll-like receptor 2 (TLR2) which is weak in few cardiac muscle cells (arrows) in the control group (8A), strong in many cardiac muscle cells (arrows) in the Methotrexate -treated group (8B) and moderate in some cardiac muscle cells (arrows) in the Methotrexate-Citrulline treated group (8C). (TLR2 immunostaining, $\mathrm{x} 400$; scale bar=30um).

\section{II-Morphometric and Statistical Results:- Area percentage (\%) of collagen fibers:}

Statistical analysis of the area \% of collagen fiber content showed a highly significant increase in the Methotrexate-treated group (II) as compared to control group (I). However, there was a non-significant increase in the Methotrexate- Citrulline treated group (III) as compared to control group (I) (Table1; Histogram 1).

\section{Optical density of TLR2 immunoexpression:}

Statistical analysis of the optical density of TLR2 positive immunoexpression showed a highly significan increase in the Methotrexate-treated group (II) as compared to control group (I). However, there was a non-significant increase in the Methotrexate- Citrulline treated group (III) as compared to control group (I) (Table1; Histogram 1).

Table 1: Morphometric and Statistical analysis of heart specimens among the studied groups:

\begin{tabular}{llll}
\hline Parameters & Group I & Group II & Group III \\
\hline $\begin{array}{l}\text { Area percentage } \\
\text { of collagen fibers }\end{array}$ & $1.02 \pm 0.01$ & $1.87 \pm 0.05^{++}$ & $1.54 \pm 0.02^{\mathrm{ss}}$ \\
$\begin{array}{l}\text { Optical density } \\
\text { of TLR2 }\end{array}$ & $12.88 \pm 1.58$ & $25.89 \pm 1.25^{++}$ & $18.08 \pm 2.56^{\mathrm{ss}}$ \\
immunoexpression & & & \\
\hline
\end{tabular}

Data are expressed as the mean \pm Standard deviation (SD).

++ : Highly significant when comparing Methotrexate-treated group (II) with control group (I) ( $p$ value $<0.001)$.

Ns: Non- significant difference when comparing MethotrexateCitrulline treated group (III) with control group (I) ( $p$ value $>0.05$ ).

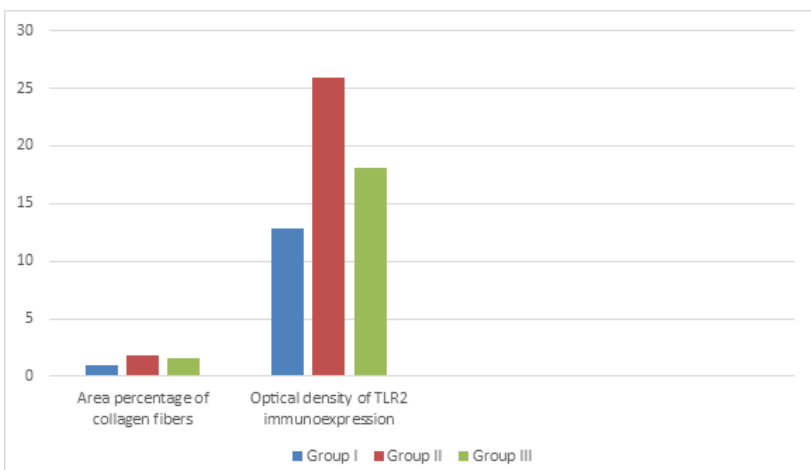

Histogram 1: showing morphometric and statistical analysis of heart specimens among studied groups.

\section{DISCUSSION}

Methotrexate is a corner stone of treatment for malignant and autoimmune diseases ${ }^{[16]}$. The broad range of antitumor activity of methotrexate is reflected in the large number of malignant diseases for which it is included in treatment regimens. Also, methotrexate has anti-inflammatory and immunomodulating properties, which allows for its use in a wide range of therapeutic indications across multiple specialties $^{[17]}$.

All rats used in this study were males to avoid any effect of the gender on the results especially the cyclic hormonal pattern of females. Moreover, gender difference has been mentioned as one of the risk factors in the toxic effects of anticancers as females show more severe cardiotoxicity with more depressed contractility than males ${ }^{[18]}$. 
MTX-treated group showed that left ventricular cardiomyocytes lost their striation and contained pyknotic nuclei. That could be explained by Ravi Rajagopalan and his colleges who reported that the anti-proliferative action of MTX depends on the inhibition of dihydrofolate reductase enzyme which is necessary for DNA production ${ }^{[19]}$.

The myocardial fibers of rats in MTX-treated group were infiltrated by inflammatory cells with congested blood vessels in between the cardiomyocytes. That is in agreement with Morsy and El-Kholy who reported cellular infiltration in the mucosal folds of fallopian tubes of MTX treated rats $^{[20]}$. Also, Chelab and Majeed documented congested glomeruli in the kidney MTX treated mice ${ }^{[21]}$.

It was reported that despite the immunosuppressive effect of high dose of MTX, it does not suppress the cytokine release from peritoneal macrophages which attract more and more inflammatory cells to the field ${ }^{[22]}$. Also, the congested blood vessels are attributed to the role of MTX in increasing the prostaglandin synthesis which leads to smooth muscle relaxation with vasodilatation ${ }^{[23]}$.

In the present work, cardiomyocytes vacuolations were observed in MTX -group. Also, E.M ultrathin sections showed cardiomyocytes with small vacuoles. That is in agreement with Al-Ali and his colleagues who observed the same result on liver cells ${ }^{[24]}$. They explained the result by the destructive effect of the accumulated toxic metabolites inside the hepatocytes on the cell membranes with subsequent hydropic degeneration and vacuolation of them. Also, MTX has a peroxidative effect on the polyunsaturated lipid on the cell membranes which disturb the intracellular water and electrolytes distribution ${ }^{[25]}$.

In the current work, MTX -group showed marked increase of collagen fibers in between cardiomyocytes which were demonstrated in the Mallory trichrome stained sections. Also, E.M ultrathin sections showed bundles of collagen fibrils in between the cardiomyocytes and confirmed statistically by a significant increase of the mean area percentage of collagen fibers in comparison to the control group. That is in agreement with some authors who reported increase of collagen fibers in the liver of MTX ratgroup around the central vein, portal tract and the plates of cells more than the control group ${ }^{[26]}$.

Fibroblasts are found throughout the cardiac tissue, surrounding cardiomyocytes and bridging between myocardial tissue layers. Inflammation is frequently associated with myocardial remodeling involving fibrosis. The fibroblasts maintain their proliferative potential which is absent in myocytes of the adult heart ${ }^{[27]}$. Certain conditions like inflammation and increase the free radicals formation caused by MTX stimulate fibroblasts proliferation and formation of collagen ${ }^{[28]}$.
The MTX group showed marked increase of immunoreactions for TLR2 (toll like receptor2) which are expressed normally by cardiomyocytes to recognize pathogens and trigger innate immune responses ${ }^{[29]}$ in comparison to the control group.

Frantz and his colleagues explained the role of TLR2 in the tissue damage by activating nuclear factor kappa B (NF$\kappa \mathrm{B})$ and translocating it from the cytoplasm to the nucleus with stimulating various target gene expressions related to tissue damage. Also, NF- $\kappa B$ initiates the expression of proinflammatory cytokines (e.g. interleukin-6) and promotes apoptosis by activating the expression of proapoptotic proteins, such as p53, Fas, Fas ligand, and death receptor $6^{[30]}$.

Also, other authors reported that TLR2 can bind to apoptotic debris which leads to the recruitment of leukocytes, which produces diverse cytokines and chemokines $^{[31]}$.

Dilated distorted mitochondria were observed inbetween the fragmented myofibrils of methotrexate- treated group. Also, interrupted intercalated discs appeared inside the cardiomyocytes. Mitochondrial damage is triggered by increased production of ROS caused by MTX therapy. It induces toxic effect on intercalated discs and mitochondrial dysfunction with decreasing ATP synthesis ${ }^{[32]}$.

MTX + Citrulline-group revealed preservation in the histological structure of ventricular cardiomyocytes. They appeared with vesicular nuclei with mild wide intercellular spaces. Zhou and his colleagues reported that citrulline can promote the synthesis of arginine (ARG) and improve its action in reducing cell apoptosis ${ }^{[33]}$.

Less congested blood vessels appeared in between the cardiomyocytes. That could be explained by that nitric oxide (NO) produced from citrulline regulates endotheliumdependent vasodilatation, prevents the adhesion of blood cells and platelets along the endothelial cell layer of blood vessels, decreases their congestion and inhibits vascular smooth muscle cell proliferation ${ }^{[34]}$.

Trichrome stained sections of MTX + Citrulline-group showed mild increase in the collagen fibers between the cardiomyocytes. It was reported that citrulline regulates the formation of NO produced by ARG and prevents NO overproduction with less inflammatory reaction and weak stimulation to fibroblasts ${ }^{[35]}$.

Also, immunohistochemical reaction for TLR2 showed mild decrease in comparison to the MTX-group which can explained by decreasing the inflammatory effect of MTX by NO. Also, it has scavenging effects against oxygen radical species ${ }^{[36]}$, improves microcirculation and decreases endotoxemia ${ }^{[37]}$. 
Also, arginine and its precursor citrulline play an important role in the immune response during inflammation. Maintaining the arginine availability during inflammatory conditions is of crucial importance, probably best by enhancing the citrulline concentration, preventing NOS uncoupling and maintaining adequate enzyme function during these conditions ${ }^{[38]}$.

In contrast, some authors reported that the use of MTX in rheumatoid arthritis (RA) is associated with a decreased risk of clinical CVD morbidity and mortality ${ }^{[39]}$. The reduction in CVD events may occur very early in the disease course even before the diagnosis of RA which raises the exciting prospect that MTX use very early in the disease course may not only delay the onset of RA but may also reduce the risk of collateral damage such as atherosclerosis ${ }^{[40]}$.

\section{CONCLUSION}

There is evidence that MTX has harmful effect on the heart. Addition of Citrulline to MTX regimen decreases its harmful effects with improvement of the histology of the heart. So, the low dose of MTX needs further studies to determine its actual effect on the heart events.

\section{ACKNOWLEDGMENTS:}

The authors thank Dr. Samah Mohamed for her assistance in performing morphometric measurements and statistical analysis of the results.

\section{CONFLICT OF INTEREST}

There are no conflicts of interest.

\section{REFERENCES}

1. Vardi N, Parlakpinar H, Cetin A, Erdogan A, Ozturk I. Protective e $\square$ ect of $\beta$-carotene on methotrexate induced oxidative liver damage. Toxicol Pathol 2010;38:592-597

2. Antunes NL, Souweidane MM, Lis E, Rosenblum MK, Steinherz PG. Methotrexate leukoencephalopathy presenting as Kluver-Bucy syndrome and uncinate seizures. Pediatr Neurol 2002;26:305-308

3. Uraz V, Tahan C, Aygun. Role of ursodeoxycholic acid in prevention of methotrexate-induced liver toxicity. Digestive Diseases and Sciences. 2008; 53:1071-1077

4. Kintzel PE. Anticancer drug-induced kidney disorders. Drug Safety. 2001; 24:19-38
5. Perez-Verdia A, Angulo F, Hardwicke L, Nugent K. Acute cardiac toxicity associated with highdose intravenous methotrexate therapy: case report and review of the literature. Pharmacotherapy: The Journal of Human Pharmacology and Drug Therapy. 2005;25:1271-1276

6. Usman D, Frank S, Gabriel A. Effects of L-arginine and L-citrulline on IndomethacinInduced Gastric Ulceration and Gastric $\mathrm{pH}$ in Male Albino Rats. European Journal of Medicinal Plants. 2014;4:623-640

7. SchwedhelmE, Maas R, Freese R. Pharmacokinetic and pharmacodynamic properties of oral L-citrulline and L-arginine: impact on nitric oxide metabolism. Br. J. Clin. Pharmacol. 2008;65:5159

8. Morris S. Enzymes of arginine metabolism. J. Nutr. 2004; 134:2743-2747

9. Chao W. Toll-like receptor signaling: a critical modulator of cell survival and ischemic injury in the heart. Am J Physiol Heart Circ Physiol. 2009;296(1):H1-H12.

10. Bayram M, Ozogul C, Dursun A, SevimErcan Z, Dilekoz E. Light and electron microscopic examination of effects of methotrexate on the endosalpinx. Europ $\mathrm{Jr}$ of obst and gynecol and Reprod Biol. 2005;120:96-103

11. Liu Y, Tian X, Gou L, Fu X, Li S, Lan N, Yin X. Protective effect of 1-citrulline against ethanolinduced gastric ulcer in rats. Environ Toxicol Pharmacol. 2012;34: 280-287

12. Bancroft JD, Gamble M. Theory and practice of histological techniques. 6th ed. Philadelphia: Churchill Livingstone: Elsevier Health Science. 2008:126-127

13. Ramos-Vara JA, Kiupel M, Baszler T, Bliven L, Brodersen B, Chelack B. Suggested guidelines for immunohistochemical techniques in veterinary diagnostic laboratories. $\mathrm{J}$ Vet Diagn Invest. 2008;20: 393-413

14. Glauret A, Lewis P. Biological Specimen Preparation for Transmission Electron Microscopy. 1st ed. Portland Press London. 1998;17

15. Dawson-Saunders B, Trapp R. Basic and clinical biostatics. 3rd ed. New York. Lang Medical Book, McGrow Hill Medical Publishing Division. 2001;161-218 
16. Wessels JA, Huizinga TW, Guchelaar HJ. Recent insights in the pharmacological actions of methotrexate in the treatment of rheumatoid arthritis. Rheumatology Oxford 2008;47:249-255

17. Yarris JP, Hunter AJ. The cure of choriocarcinoma and its impact on the development of chemotherapy for cancer. Gynecol Oncol 2003;89:193-198

18. Ezaz G, Long JB, Gross CP, Chen J. Risk prediction model for heart failure and cardiomyopathy after adjuvant trastuzumab therapy for breast cancer. J Am Heart Assoc 2014;3(1):472

19. Rajagopalan PT, Zhang Z, McCourt L, Dwyer M, Benkovic SJ, Hammes GG. Interaction of dihydrofolate reductase with methotrexate, Ensemble and single-molecule kinetics. Proc Natl Acad Sci USA. 2002; 99:13481-13486

20. Morsy SE, El-Kholy S. The effect of methotrexate on the fallopian tubes of adult albino rats, a histological and immunohistochemical study. The Egyptian Journal of Histology. 2012; 35:833-839

21. Chelab K, Majeed SS. Methotrexate-induced histopathological changes in the kidneys of mice. Iraqi Journal of Veterinary Sciences. 2009;22:219-222

22. Ravelli A, Caria MC, Buratti S, Malattia C, Temporini F, Martini A. Methotrexate as a possible trigger of macrophage activation syndrome in systemic juvenile idiopathic arthritis. The Journal of Rheumatology. 2001;28:865 -867

23. Walter JB, Israel M. Inflammation-In, Walter and Israel general pathology. 7th ed: Churchill Livingstone, New York. 1996;167

24. Al-Ali SY, Hassan IM, Sadek S. Ultrastructural changes in rat livers perfused in vitro and in vivo with a high dose of methotrexate. Histol Histopathol 2005; 20:1131-1145

25. Gulgun M, Karaoglu A, Kesik VS, Kurt B, Ozcan O. Effect of proanthocyanidin, arginine and glutamine supplementation on methotrexateinduced gastrointestinal toxicity in rats. Methods Find Exp Clin Pharmacol. 2010; 32:657-661

26. Sayed MM, Abdel-maksoud SA, Nasr AN, Sayed AA. Effects of methotrexate ( $\mathrm{mtx}$ ) on the structure of liver and kidney of adult male albino rats and the role of folic acid. AAMJ. 2006;4:1687-1693
27. Camelliti P, Borg TK, Kohl P. Structural and functional characterization of cardiac fibroblasts. Cardiovascular research. 2005;65(1):40-51

28. Beltrami AP, Urbanek K, Kajstura J,Yan SM, Finato N, Bussani R. Evidence that human cardiomyocytes divide after myocardial infarction. N Engl J Med 2001;344:1750-1757

29. Kwame A, Darfour-Oduro, Jan Megens H, Schook L. Evidence for adaptation of porcine Toll- like receptors. Immunogenetics. 2016;68:179-189

30. Frantz S, Kelly RA, Bourcier T. Role of TLR2 in the activation of nuclear factor kappaB by oxidative stress in cardiac myocytes. J Biol Chem 2001; 276:5197-5203

31. Abarbanell AM, Wang Y, Herrmann JL, Weil BR, Poynter JA, Manukyan MC, et al. Toll-like receptor 2 mediates mesenchymal stem cell-associated myocardial recovery and VEGF production following acute ischemia reperfusion injury. Am J Physiol Heart Circ Physiol. 2010;298:1529-1536

32. Kolli VK, Natarajan K, Isaac B, Selvakumar D, Abraham P. Mitochondrial dysfunction and respiratory chain defects in a rodent model of methotrexate-induced enteritis. Hum Exp Toxicol. 2014;33:1051-1065

33. Zhou JQ, Xu X, Zhen WW, Luo YL, Cai B, Zhang S. Protective Effect of Citrulline on the Hearts of Rats with Sepsis Induced by Cecal Ligation and Puncture. Biomed Res Int. 2018;1-10

34. Ignarro LJ, Buga GM, Wei LH. Role of the arginine-nitric oxide pathway in the regulation of vascular smooth muscle cell proliferation. Proc Natl Acad Sci. 2001;98:4202-4208

35. Zhang WY, Takiguchi M, Koshiyama Y, Gotoh T, Nagasaki A, Iwase K, Yamamoto K, Takeshima H, Negi A, Mori M. Expression of citrulline-nitric oxide cycle in lipopolysaccharide and cytokinestimulated rat astroglioma C6 cells. Brain Res1999; 849:78-84

36. Napoli C, Ackah E, De Nigris F. Chronic treatment with nitric oxide-releasing aspirin reduces plasma low-density lipoprotein oxidation and oxidative stress, arterial oxidation-specific epitopes, and atherogenesis in hypercholesterolemic mice. Proc Natl Acad Sci. 2002;99:12467-12470 
37. Wijnands KA, Vink H, Briedé JJ. Citrulline a more suitable substrate than arginine to restore NO production and the microcirculation during endotoxemia. PLoS One. 2012;7:1-11

38. Wijnands KA, Castermans TM, Hommen MP, Meesters DM, Poeze M. Arginine and citrulline and the immune response in sepsis. Nutrients 2015; 7(3):1426-1463
39. Endean A. The risk of stroke in patients with rheumatoid arthritis compared to the general population, Abstract, Arthritis. Rheum. 2007;56: 293

40. Sarah L, Alexandra NW, Baird J, Kiely P, Quinn M, Ernest Choy. The effect of methotrexate on cardiovascular disease in patients with rheumatoid arthritis: a systematic literature review. Rheumatology. 2010;49:295-307 


$$
\text { الملخص العربى }
$$

\section{دور السيترولين فى حماية عضلة القلب من التأثير السام للميزوتريكسيت في ذكور الجرذان البيضاء (دراسة هستولوجية وهستوكيميائية مناعية)}

\section{غادة عبد العزيز السماك ـ سمر عبد العزيز مصطفى ـ سمر محمد رضا}

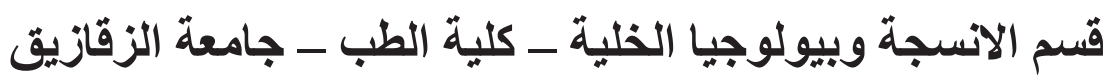

المقدمة: بستخدم الميزوتريكسيت على نطاق واسع لعلاج أمر اض الأورام والكثير من الامر اض الاخري على الرغم من آثاره

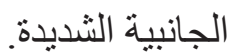

الغرض من البحث: دراسة الحماية المحتملة للسيترولين على التغيرات الهستولوجية الناتجة عن استخدام الميزوتريكسيت.

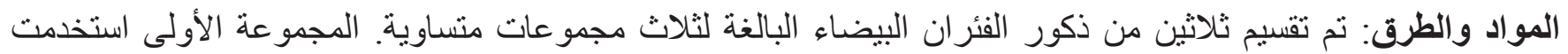

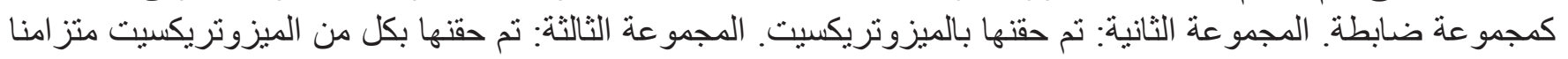

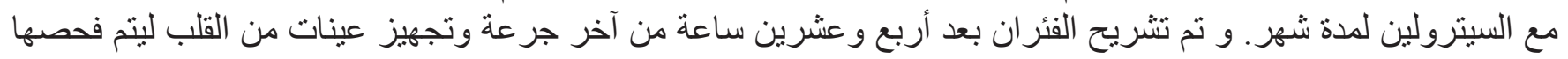
بالميكروسكوب الضوئي و الالكتروني.

النتائج: ظهرت تغير ات تحللية في المجمو عة التي نلقت الميزوتريكسيت منفردا فى حين أظهرت عينات المجمو عه التي عولجت

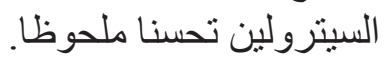
الإستتاج: استخدام السيترولين يساعد في حمايه عضلة القلب من التأثير السام للميزوتريكسيت. 